\title{
New Frontiers in Biocatalysis for Sustainable Synthesis
}

\author{
Woodley, John M.
}

\section{Published in:}

Current Opinion in Green and Sustainable Chemistry

Link to article, DOI:

10.1016/j.cogsc.2019.08.006

Publication date:

2019

Document Version

Peer reviewed version

Link back to DTU Orbit

Citation (APA):

Woodley, J. M. (2019). New Frontiers in Biocatalysis for Sustainable Synthesis. Current Opinion in Green and Sustainable Chemistry, 21, 22-26. https://doi.org/10.1016/j.cogsc.2019.08.006

\section{General rights}

Copyright and moral rights for the publications made accessible in the public portal are retained by the authors and/or other copyright owners and it is a condition of accessing publications that users recognise and abide by the legal requirements associated with these rights.

- Users may download and print one copy of any publication from the public portal for the purpose of private study or research.

- You may not further distribute the material or use it for any profit-making activity or commercial gain

- You may freely distribute the URL identifying the publication in the public portal

If you believe that this document breaches copyright please contact us providing details, and we will remove access to the work immediately and investigate your claim. 


\section{New Frontiers in Biocatalysis for Sustainable Synthesis}

John M Woodley

Department of Chemical and Biochemical Engineering, Technical University of Denmark (DTU), DK-2800 Kgs Lyngby, Denmark (jw@kt.dtu.dk)

\section{Keywords}

Biocatalysis, Enzyme catalysis, Multi-step enzymatic reactions, Flow biocatalysis

Today enzymatic catalysis is widely used in the pharmaceutical industry and is expanding fast into the fine and specialty chemicals sector, driven by the need for evermore sustainable chemistry. This review highlights the increasing emphasis now placed on achieving better process performance metrics to reflect the demand for cost-effective and scalable processes, ready for direct implementation into industry. The review also highlights other developments at the frontiers of this field including flow chemistry and multi-step enzymatic reactions, which benefit sustainability.

\section{Introduction}

Biocatalysis uses enzymes to catalyze chemical reactions in a highly selective manner, usually under mild reaction conditions. The number of biocatalytic applications continues to expand and today the use of enzymatic synthesis is commonplace in the pharmaceutical industry [1] and developing rapidly in the fine and specialty chemicals sector. Aside from catalysis with high selectivity under benign conditions, there are several other reasons for this expansion. For example, most biocatalytic reactions occur in water, which makes for simplified liquid waste treatment. Likewise, enzymatic catalysts are renewable. Indeed, the renewable nature of enzyme catalysts should not be overlooked, since it brings significant benefits from and environmental perspective as well as stable catalyst costs. All these benefits were summarized recently in an important review highlighting the enormous potential of biocatalysis to satisfy the requirements of sustainable chemical synthesis [2](Table 1). However, despite this progress, some barriers to implementation still need to be overcome [3,4]. For example, in the pharmaceutical sector increasing development speed is paramount [5]. However, it is in the synthesis of lower value products that the major challenges for the future exist. An excellent recent review about the use of biocatalysis targeted at the production of bulk n-alkyl amines, highlighted the need for higher substrate loadings and higher productivities (space-time yields)[6]. Indeed, while many industrial chemical processes are extremely well optimized and thereby bring significant economic return, in many cases they are not sustainable due to poor selectivity, high energy 
demand and the use of non-renewable reactants, reagents and catalysts. By contrast, enzymatic reactions discovered in the laboratory are frequently found to be good from the perspective of green chemistry, but are often limited in terms of economic potential (schematically illustrated in Figure 1). These demands therefore place significant emphasis on the need for translational research to convert laboratory reactions into industrial processes. Several recent trends reflect these needs (Table 2) and will be further discussed in this brief review.

\section{Designing 'better' biocatalytic processes}

Against this background, it is interesting that a recent trend in the field of biocatalysis has been the design and development of 'better' biocatalysts, biocatalytic reactions and biocatalytic processes. The target now is invariably to get enzyme reactions to operate closer to commercially-viable industrial conditions. Such conditions demand process performance metrics far from those seen in the laboratory. Nevertheless assessing the productivity (e.g. g product / L reactor. h), yield of product on biocatalyst (e.g. g product / g biocatalyst), yield of product on substrate (e.g. g product /g substrate), as well as product concentration (e.g. g product / L reactor) can be very valuable to benchmark processes and set targets for improvement $[7,8]$. Unlike chemical catalysis, where the process is in general designed to fit particular catalyst properties, in biocatalysis the option of engineering the enzyme (so called protein engineering) can enable enormous improvement in the biocatalyst properties [9]. Clearly, judicious selection of the starting point for protein engineering or evolution can also help the effectiveness of enzyme improvement [10]. Today, protein engineering technologies, using directed evolution linked with experimental screening, or using computational tools to guide protein modification, or even combinations of these approaches have gained widespread acceptance and considerable traction [11]. The latest developments in automated technology are now also contributing to the speed with which such methods can be applied [12]. In many ways such protein tuning technologies provide an extra degree of freedom in process design [13]. More recently such approaches have been used not only to assist in the adaption of a given enzyme to exciting new chemistry, but also assisting with modifying those enzyme properties that directly affect the process performance [14]. For example the synthesis of Vibergon using a ketoreductase that specifically targeted at high $\mathrm{pH}$ dynamic kinetic resolution (DKR) was recently reported [15].

A relatively new class of enzymes for synthesis of cyclic and acyclic amines are the NAD(P)H imine reductases (IREDs)[16,17]. A remarkable publication recently described the technical development required to scale-up such enzymatic systems for reductive amination [18]. Using a combination of protein engineering and process engineering the authors reported excellent volumetric productivities of $12.9 \mathrm{~g} / \mathrm{L} . \mathrm{h}$ for the reductive amination of model compounds cyclohexanone with cyclopropylamine to form a secondary amine. It is interesting that both protein engineering and process engineering were required to achieve such a result, and that the excellent volumetric productivities were achieved at such high turnover numbers (TONs), above 48000 . TON is defined as the number of moles of substrate (or reactant) converted by a mole of enzyme, before it is inactivated. In the example here it was calculated based on the molar 
concentration of product formed divided by the molar concentration of enzyme used to form that product.

Another excellent example concerns the synthesis of aliphatic nitriles using an aldoxime dehydratase from Bacillus sp. (OxB-1) at substrate loadings of $1.4 \mathrm{~kg} / \mathrm{L}$ [19]. This sets a new precedent for substrate concentration in biocatalysis and indeed the use of high substrate concentrations, and thereby resulting high product concentrations, is of vital importance not only to ensure cost-effective downstream processing, but also to minimize the water use in the process and hence reduce the $E$ factor (kg waste/kg product)[20]. Likewise a new process for the synthesis of (S)-2-chloro-1-(3,4-difluorophenyl)ethanol using a ketoreductase has also been reported operating with substrate loadings of $0.5 \mathrm{~kg} / \mathrm{L}$ [21], and an enzymatic process for the production of (R)-2-butyl-2-ethyloxirane reported at $0.3 \mathrm{~kg} / \mathrm{L}$ [22].

Other process related improvements continue to focus on in situ product removal (ISPR) technologies with an excellent pilot scale demonstration reported using enzymatic reactive distillation [23], as well as more fundamental studies on enzymatic reactive crystallization [2426], and an important review focused on in situ product crystallization for the improvement of biocatalytic processes [27].

Further work is still required to develop even better biocatalytic reactions and processes targeting not only high yields, but also to reduce the excess of co-substrates in two substrate reactions, as highlighted in a recent review defining future targets for accelerating the implementation of biocatalysis into industry [28].

\section{Flow biocatalysis}

A second major trend in biocatalysis in the last few years has been to embrace the development in synthetic organic chemistry towards flow synthesis [29]. Several excellent reviews have been published covering the fundamentals of this approach with a particular focus on biocatalysis [3033]. It is clear that while enzymatic reactions are relatively slow, in many cases significant advantages can be gained from shifting to flow on account of a defined residence time, as well as reduced downtime for tank loading, emptying and cleaning. The former capitalizes upon the selectivity already at work when using enzymes for synthesis and the latter enables smaller reactor footprints, with the option of on-line instrumentation to control production in real time. Many of the flow approaches suggested to date rely on some type of enzyme entrapment, usually via immobilization on (or in) a support [34-36]. The drive towards a more generic method remains important [37], but dependent upon the required residence time, pressure drop considerations in flow can also be limiting. Hence in some cases alternative reactors will be required for continuous operation. A further driver for alternative reactors may come from the kinetic profile of the enzyme, where high Michaelis constants mean operation needs to take place in a plug-flow regime. Such an approach is possible in non-tubular systems using a series of stirred tank reactors. Several recent publications have highlighted the importance of choosing 
the appropriate reactor configuration to best fit the kinetic profile of a given enzyme-catalyzed reaction $[38,39]$. Several reports have also indicated novel methods of control including using light-dependent activation.

In the last few years' interest in oxidative reactions using enzymes (driven by sustainability requirements) has expanded enormously [40]. Biocatalytic oxidation attracts particular interest as a sustainable route to alcohols and aldehydes [41]. An excellent recent example concerns the synthesis of (R)-1-(4'-hydroxyphenyl)ethanol using vanillyl alcohol oxidase [42]. Indeed oxidases are of particular interest since they do not require additional cofactors. The interest in oxidation has also led to several approaches attempting the difficult problem of oxygen supply to an aqueous biocatalytic system in flow. Such approaches have included the biocatalytic degradation of $\mathrm{H}_{2} \mathrm{O}_{2}$ using catalase to yield supersaturated concentrations of oxygen [43], tube-in-tube reactors operating up to 10 bar pressure [44], single tube reactors up to 34 bar pressure [45], and photo-biocatalytic methods to generate oxygen in situ in the liquid phase [46]. The best approach in a particular case is still unclear, but is of course dependent upon the economic requirements of a given reaction.

\section{Multi-step biocatalysis}

Many current biocatalytic methods use a single step in a synthesis that may contain many other catalytic (or even stoichiometric) reaction steps. From a green chemistry perspective it is of course important to try to make as many of the steps as possible biocatalytic, also to avoid the need for changing conditions (e.g. temperature, $\mathrm{pH}$, pressure, solvent) in the middle of the synthetic scheme. Multi-step biocatalysis allows cascades of enzyme reactions to be integrated and huge progress has been made in this field in recent years $[47,48]$. An excellent example of a small cascade concerns the asymmetric synthesis of L- and D-homoalanine. Here for the first time, the synthesis of both enantiomers of an important unnatural amino acid was demonstrated using combinations of L-methionine $\Upsilon$-lyase, and D or L-amino acid aminotransferase [49]. More complex syntheses have also been proposed, and in some cases successfully demonstrated. In many of these cases, the use of modelling has been instrumental in designing a suitable experimental approach since the number of variables escalates very quickly [50]. A particularly interesting example concerns the seven enzyme system based around carboxylic acid reductases (CARs) [51]. In vitro such enzymes require the regeneration of cofactors, and in many cases this can become limiting. A recent study on an enzymatic cascade in vivo connecting the oxidation of secondary alcohols by an alcohol dehydrogenase (ADH), a Michael reduction by an enoate reductase (ERED), and a Baeyer-Villiger oxidation by a Baeyer-Villiger monooxygenase (BVMO), identified the limitations caused by cofactors, using kinetic modelling [52].

\section{Tools for evaluation of green and sustainable biocatalysis}

Whilst improvements are made to the economic return associated with implementing new biocatalytic processes, it is clear that systematic evaluation of reactions and processes is of vital 
importance, if only to benchmark progress and set targets for those involved in research and development. A set of economic metrics has been developed in recent years with which to assess progress towards the ultimate goal of industrial implementation. Such metrics are of necessity somewhat simplified and therefore do not always give an accurate picture in every case, but they serve (especially at a very early stage in the laboratory) to guide further research and development. A parallel set of green chemistry metrics might be based on $E$ factor [53] or the process mass intensity (PMI)). This is also simplified but can be combined with other metrics such as water intensity or solvent intensity. A suggested set of economic and green chemistry metrics (and their definitions) is given in Table 3. An increasing number of processes are being compared using still more detailed analyses such a life cycle analysis (LCA). Several comparisons between enzymatic and chemical conversions have now been reported, although a recurring challenge is the limited data on enzyme production, which can be of great importance in enzymatic reactions that have a low yield of product on biocatalyst. Meanwhile a prospective LCA was recently published showing the value of comparisons between alternative processes at an early stage, with a view to guiding further research and development [54].

\section{Conclusions}

Biocatalysis continues to develop as a major opportunity to improve the sustainability of methods for organic synthesis and production. In recent years, many new classes of enzymes have become available, and protein engineering techniques continue to open the possibilities for tuning enzyme properties dependent upon operation and scale-up needs. Increasing efforts on improving processes now mean that examples from the laboratory start to match the target metrics set by economic needs. Other developments are in the area of flow biocatalysis and also multi-step biocatalysis, both of which also deliver improved sustainability. Finally, developments in the benchmarking of processes using green chemistry and economic metrics also enable quantitative assessment of progress to be made.

\section{Conflict of interest}

Nothing declared.

\section{References}

[1] Devine PN, Howard RM, Kumar R, Thompson MP, Truppo MD, Turner NJ: Extending the application of biocatalysis to meet the challenges of drug development. Nature Rev Chem 2018, 2:409-421.

[2] Woodley JM, Sheldon RA: The role of biocatalysis in sustainable chemistry. Chem Rev 2018, 118:801-834.

${ }^{\circ}$ Seminal review of the role of biocatalysis in the development of new methods in sustainable chemistry. 
[3] Reetz MT: What are the limitations of enzymes in synthetic organic chemistry? Chem Rec 2016, 16:2449-2459.

[4] Sheldon RA, Brady D: The limits to biocatalysis: pushing the envelope. Chem Commun 2018, 54:6088-6104.

[5] Truppo MD: Biocatalysis in the pharmaceutical industry: The need for speed. ACS Med Chem Lett 2017, 8:476-480.

'Important paper emphasizing the need for a paradigm shift in the speed of development of new biocatalytic processes in the pharmaceutical industry.

[6] Gröger H: Biocatalytic concepts for synthesizing amine bulk chemicals: Recent approaches towards linear and cyclin aliphatic primary amines and $\omega$-substituted derivatives thereof. Appl Microbiol Biotechnol 2019, 103:83-95.

[7] Lima-Ramos J, Tufvesson P, Woodley JM: Application of environmental and technoeconomic metrics to biocatalytic process development. Green Proc Synth 2014, 3:195213.

[8] Nordblad M, Dias Gomes M, Meissner MP, Ramesh H, Woodley JM: Scoping biocatalyst performance using reaction trajectory analysis. Org Proc Res Dev 2018, 22:1101-1114.

[9] Bornscheuer UT: The fourth wave of biocatalysis is approaching. Phil Trans R Soc (Lond) A 2017, 376:20170063.

[10] Trudeau DL, Tawfik DS: Protein engineers turned evolutionists - the quest for the optimal starting point. Curr Opin Biotechnol 2019, 60:46-52.

[11] Arnold FH: Directed evolution: Bringing new chemistry to life. Angew Chem Int Ed 2018, 57:4143-4148.

${ }^{\circ}$ Important paper reviewing the latest developments in the field of directed evolution. The author was awarded half of the Nobel Prize in Chemistry in 2018 for her contributions to the field of directed evolution.

[12] Diefenbach XW, Farasat I, Guetschow ED, Welch CJ, Kennedy RT, Sun S, Moore JC: Enabling biocatalysis by high-throughput protein engineering using droplet microfluidics coupled to mass spectrometry. ACS Omega 2018, 3:1498-1508.

[13] Woodley JM: Integrating protein engineering with process design for biocatalysis. Phil Trans R Soc (Lond) A 2017, 376:20170062.

${ }^{\circ}$ This article illustrates the concept of optimal process design using an approach to integrate engineering of the process and engineering of the biocatalyst. 
[14] Woodley, J.M: Protein engineering of enzymes for process applications. Curr Opin Chem Biol 2013, 17:310-316.

[15] Xu F, Kosjek B, Cabirol FL, Chen H, Desmond R, Park J, Gohel AP, Collier SJ, Smith DJ, Liu Z, Janey JM, Chung JYL, Alvizo O: Synthesis of Vibegron enabled by a ketoreductase rationally designed for high $\mathbf{p H}$ dynamic kinetic resolution. Angew Chem Int Ed 2018, 57:6863-6867.

[16] Scheller PN, Fademrecht S, Hofelzer S, Pleiss J, Leipold F, Turner NJ, Nestl BM, Hauer B: Enzyme toolbox: Novel enantiocomplementary imine reductases. ChemBioChem 2014, 15:2201-2204.

[17] Lenz M, Borlinghous N, Weinmann L, Nestl BM: Recent advances in imine reductivecatalyzed reactions. World J Microbiol Biotechnol 2017, 33:199.

[18] Bornadel A, Bisagni S, Pushpanath A, Montgomery SL, Turner NJ, Dominguez B: Technical considerations for scale-up of imine-reductase-catalyzed reductive amination: a case study. Org Proc Res Dev 2019, 23:1262-1268.

${ }^{\circ}$ Seminal article describing the improvements in the development of an IRED process, suitable for commercialization.

[19] Hinzmann A, Glinski S, Worm M, Gröger H: Enzymatic synthesis of aliphatic nitriles at a substrate loading of up to $1.4 \mathrm{~kg} / \mathrm{L}$ : A biocatalytic record achieved with a heme protein. J Org Chem 2019, 84:4867-4872.

[20] Ni Y, Holtmann D, Hollmann F: How green is biocatalysis? To calculate is to know. ChemCatChem 2014, 6:930-943.

${ }^{\circ}$ Important article emphasizing the importance of product concentration to attain adequate green chemistry metrics.

[21] Guo X, Tang J-W, Ni G-W, Zhang F-L, Chen S-X: Development of a practical enzymatic process for preparation of $(S)$-2-chloro-1-(3,4-difluoropjenyl)ethanol. Org Proc Res Dev 2017, 21:1595-1601.

[22] Roiban G-D, Sutton PW, Splain R, Morgan C, Fosberry A, Honicker K, Homes P, Boudet C, Dann A, Guo J, Brown KK, Ihnken LAF, Fuerst D: Development of an enzymatic process for the production of (R)-2-butyl-2-ethyloxirane. Org Proc Res Dev 2017, 21:13021310.

[23] Wierschem M, Schlimper S, Heils R, Smirnova I, Kiss AA, Skiborowski M, Lutze P: Pilotscale validation of enzymatic reactive distillation for butyl butyrate production. Chem Eng J 2017, 312:106-117. 
[24] McDonald MA, Bommarius AS, Rousseau RW, Grover MA: Continuous reactive crystallization of $\boldsymbol{\beta}$-lactam antibiotics catalyzed by penicillin $\mathbf{G}$ acylase. Part I: Model development. Comput Chem Eng 2019, 123:331-343.

[25] McDonald MA, Bommarius AS, Grover MA, Rousseau RW: Continuous reactive crystallization of $\boldsymbol{\beta}$-lactam antibiotics catalyzed by penicillin $\mathrm{G}$ acylase. Part II: Case study on ampicillin and product purity. Comput Chem Eng 2019, 126:332-341.

[26] Egger T, Egger LS, Fieg G: Scale and causes of catalyst activity loss in enzymatic catalyzed reactive distillation. Chem Eng Sci 2018, 178:324-334.

[27] Hülsewede D, Meyer L-E, von Langermann J: Application of in situ-product crystallization and related techniques in biocatalytic processes. Chem Eur J 2019, 25:4871-4884.

[28] Woodley JM: Accelerating the implementation of biocatalysis in industry. Appl Microb Biotech 2019, 103:4733-4739.

[29] Britton J, Jamison TF: The assembly and use of continuous flow systems for chemical synthesis. Nature Protocols 2017, 12:2423-2446.

[30] Marques MPC, Szita N: Bioprocess microfluidics: applying microfluidic devices for bioprocessing. Curr Opin Chem Eng 2017, 18:61-68.

[31] Tamborini L, Fernandes P, Paradisi F, Molinari F: Flow bioreactors as complementary tools for biocatalytic process intensification. Trends Biotech 2018, 36:73-88.

${ }^{\circ}$ Important review summarizing the benefits, as well as future challenges, for the implementation of biocatalysis in flow.

[32] Britton J, Dyer RP, Majumdar S, Raston CL, Weiss GA: Ten-minute protein purification and surface tethering for continuous-flow biocatalysis. Angew Chem Int Ed 2017, 56:2296-2301.

[33] Bolivar JM, Valikhani D, Nidetzky B: Demystifying the flow: Biocatalytic reaction intensification in microstructured enzyme reactors. Biotechnol J 2019 DOI: 10.1002/biot.2018800244.

[34] Britton J, Majumdar S, Weiss GA: Continuous flow biocatalysis. Chem Soc Rev 2018, 47:5891-5918.

'Important review summarizing the benefits, as well as future challenges, for the implementation of biocatalysis in flow. 
[35] Thompson MP, Panafiel I, Cosgrove SC, Turner NJ: Biocatalysis using immobilized enzymes in continuous flow for the synthesis of fine chemicals. Org Proc Res Dev 2019, 23:9-18.

[36] Böhmer W, Knaus T, Volkov A, Slot TK, Shiju NR, Cassimjee KE, Mutti FG: Highly efficient production of chiral amines in batch and continuous flow by immobilized $\omega$ transaminase on controlled porosity glass metal-ion affinity carrier.J Biotechnol 2019, 291:52-60.

[37] Thompson MP, Derrington SR, Heath RS, Porter JL, Mangas-Sanchez J, Devine PN, Truppo MD, Turner NJ: A generic platform for the immobilization of engineered biocatalysts. Tetrahedron 2018, 75:327-334.

[38] Chapman MR, Kwan MHT, King G, Jolley KE, Hussain M, Hussain S, Salama IE, Nino CG, Thompson LA, Bayana ME, Clayton AD, Nguyen BN, Turner NJ, Kapur N, Blacker AJ: Simple and versatile laboratory scale CSTR for multiphasic continuous-flow chemistry and long residence times. Org Proc Res Dev 2017, 21:1294-1301.

${ }^{\circ}$ Article describing alternative reactor configurations for flow chemistry, especuially with respect to multi-phasic systems.

[39] Lindeque RM, Woodley JM: Reactor selection for effective continuous biocatalytic production of pharmaceuticals. Catalysts 2019, 9:262.

[40] Dong JJ, Fernandez-Fueyo E, Hollmann F, Paul CE, Pesic M, Schmidt S, Wang Y, Younes S, Zhang W: Biocatalytic oxidation reactions - a chemist's perspective. Angew Chem Int Ed 2018, 57:9238-9261.

${ }^{\circ}$ Important review describing the role of biocatalysis in synthetic organic oxidation chemistry

[41] Liu J, Wu S, Li Z: Recent advances in enzymatic oxidation of alcohols. Curr Opin Chem Biol 2018, 43:77-86.

[42] Ewing TA, Kühn J, Segarra S, Tortajada M, Zuhse R, van Berkel WJH: Multigram scale enzymatic synthesis of ( $R$ )-1-(4'-hydroxyphenyl)ethanol using vanillyl alcohol oxidase. Adv Synth Catal 2018, 360:2370-2376.

[43] Chapman MR, Cosgrove SC, Turner NJ, Kapur N, Blacker AJ: Highly productive oxidative biocatalysis in continuous flow by enhancing the aqueous equilibrium solubility of oxygen. Angew Chem Int Ed 2018, 57:10535-10539.

${ }^{\circ}$ Novel oxygen supply methods to biocatalytic oxidations using supersaturated concentrations of oxygen aqueous phase.

[44] Ringborg RH, Toftgaard Pedersen A, Woodley JM: Automated determination of oxygen dependent enzyme kinetics in a tube-in-tube microreactor. ChemCatChem 2017, 9:3285-3288. 
${ }^{\circ}$ Novel methods of oxygen supply to biocatalytic reactions using a tube supplying oxygen surrounding a single tube reactor where the aqueous based conversion occurs.

[45] Bolivar JM, Mannsberger A, Thomsen MS, Tekautz G, Nidetzky B: Process intensification of 02-dependent enzymatic transformations in continuous single-phase pressurized flow. Biotech Bioeng 2019, 116:503-514.

[46] Hoschek A, Schmid A, Bühler B: In situ 02 generation in the liquid phase. ChemCatChem 2018, 10:5366-5371.

[47] Sperl JM, Sieber V: Multienzyme cascade reactions - Status and recent advances. ACS Catalysis 2018, 8:2385-2396.

${ }^{\circ}$ Important review on the options for multi-enzymatic cascade reactions.

[48] Schrittwieser JH, Velikogne S, Hall M, Kroutil W: Artificial biocatalytic linear cascades for preparation of organic molecules. Chem Rev 2018, 118: 270-348.

[49] Silva MVM, Costa ICR, de Souza ROMA, Bornscheuer UT: Biocatalytic cascade reaction for the asymmetric synthesis of L- and D-homoalanine. ChemCatChem 2019, 11:407411.

[50] Claaßen C, Gerlach T, Rother D: Stimulus-responsive regulation of enzyme activity for one-step and multi-step syntheses. Adv Synth Catal 2019, 9:3420-3427.

[51] Finnigan W, Cutlan R, Snajdrova R, Adams JP, Littlechild JA, Harmer NJ: Engineering a seven enzyme biotransformation using mathematical modelling and characterized enzyme parts. ChemCatChem 2019 DOI: 10.1002/cctc.201900646.

${ }^{\circ}$ Important paper describing new modelling methods for complex reaction networks using genetic algorithms.

[52] Milker S, Fink MJ, Oberleitner N, Ressmann AK, Bornscheuer UT, Mihovilovic MD, Rudroff F: Kinetic modeling of an enzymatic redox cascade in vivo reveals cofactor-caused bottlenecks. ChemCatChem 2017, 9:3420-3427.

[53] Sheldon RA: The $\boldsymbol{E}$ factor 25 years on: the rise of green chemistry and sustainability. Green Chem 2017, 19:18-43.

[54] Delgove MAF, Laurent A-B, Woodley JM, de Wildeman SMA, Bernaerts KV, van der Meer Y: A prospective life-cycle assessment (LCA) of monomer synthesis: Comparison of biocatalytic and oxidative chemistry. ChemSusChem 2019, 12:1349-1360.

${ }^{\circ}$ Article describing the role of prospective LCA for the development of biocatalytic processes. 
Table 1. Sustainable features of biocatalytic processes

Reactions Few reaction steps (often circumventing protection and deprotection strategies) Good atom economy (effective chemistry based on Nature's efficiency) Mild operating conditions (safe and favors green chemistry metrics) Aqueous media (safe and improves waste disposal)

Catalyst Renewable (expressed in bacterial and fungal hosts grown on sugar, air and water) Highly selective (the key feature of enzymes)

Tunable (using directed evolution and protein engineering) 
Table 2. Sustainability benefits of some recent developments in biocatalysis

Reaction intensification Reduced downstream costs

Reduced $E$ factor

Flow biocatalysis

Reduction in reactor footprint

Better control

Multi-step catalysis Reduction in isolation steps and solvent changes 
Table 3. Potential metrics to benchmark biocatalytic processes

Economic metrics Productivity (g product / L reactor. $\mathrm{h}$ )

Yield of product on biocatalyst (g product / g enzyme)

Yield of product on substrate (g product / g substrate)

Product concentration (g product / L reactor)

Green chemistry metrics $\quad E$ factor (g waste / g product)

$C$ factor ( $\mathrm{g} \mathrm{CO}_{2}$ equivalents / g product)

Water intensity (g water used / g product)

Solvent intensity (g solvent used / g product) 
Figure 1. Generalized schematic representation of the need for improvements in conventional chemistry and biocatalysis for implementation of sustainable processes by achieving adequate economic and green chemistry (GC) metrics.

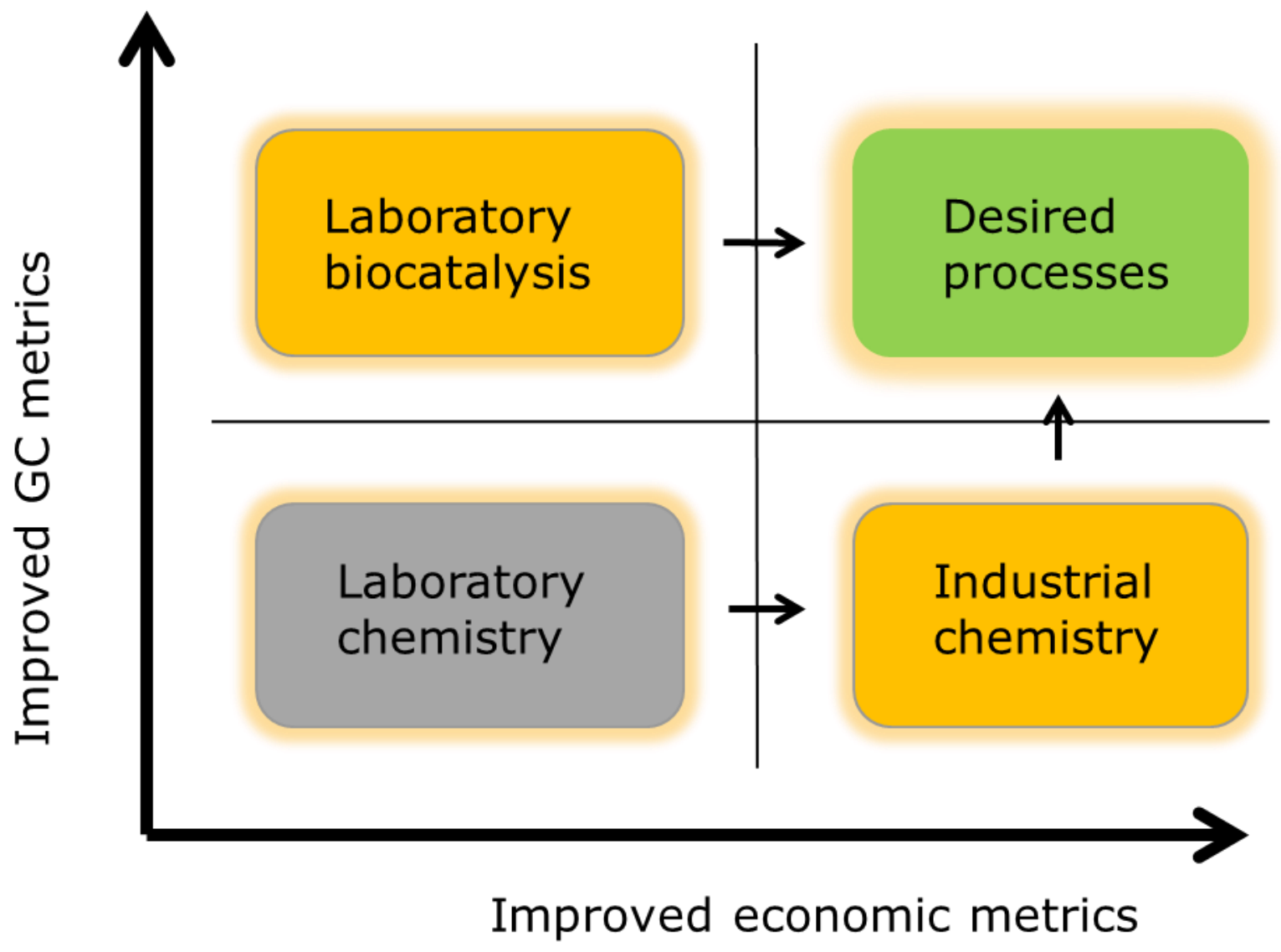

